SERRANO, R.D.C. et al. Síntese microbiana no rúmen. PUBVET, Londrina, V. 5, N. 5, Ed. 152, Art. 1025, 2011.

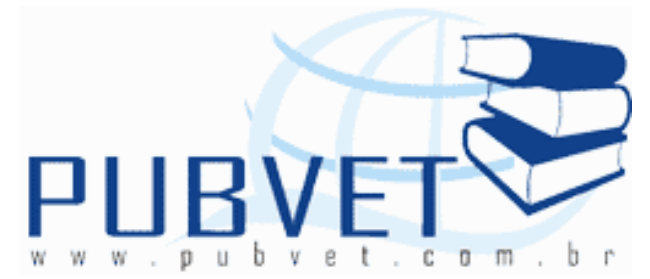

PUBVET, Publicações em Medicina Veterinária e Zootecnia.

\title{
Síntese microbiana no rúmen
}

\author{
Román David Castañeda Serrano ${ }^{1}$, Lina Maria Peñuela Sierra ${ }^{1}$, Sabrina \\ Marcantonio Coneglian², Cleiton Luiz Tonello33, Lorrayny Galoro da Silva ${ }^{4}$, \\ Beatriz da Silva Lima ${ }^{5}$
}

${ }^{1}$ Médico Veterinário e Zootecnista da Universidad Del Tolima - Colômbia. 2Zootecnista Doutora formada pela Universidade Estadual de Maringá - UEM ${ }^{3}$ Doutorando do programa de pós-graduação em Zootecnia da Universidade Estadual de Maringá - UEM.

${ }^{4}$ Mestranda do Programa de pós-graduação em Zootecnia da Universidade Estadual de Maringá - UEM.

${ }^{5}$ Graduanda do curso de Zootecnia da Universidade Estadual de Maringá UEM.

\section{Resumo}

Quantificar a síntese de proteína microbiana em animais ruminantes é de grande importância para avaliar a qualidade nutritiva das dietas. A determinação da síntese microbiana se obtém através da utilização de marcadores microbianos, os quais são classificados em internos (Subprodutos dos microrganismos ruminais) e externos (Produtos administrados aos animais que são incorporados pelos microrganismos). A pesar do grande esforço por parte dos pesquisadores nos últimos anos, ainda não se tem o marcador ideal, sendo que a maioria destes apresenta vantagens e desvantagens. Assim o 
SERRANO, R.D.C. et al. Síntese microbiana no rúmen. PUBVET, Londrina, V. 5, N. 5, Ed. 152, Art. 1025, 2011.

objetivo desta revisão é detalhar a cada uma das técnicas para estimar a síntese de proteína microbiana no rúmen e analisar e discutir os resultados obtidos utilizando cada técnica.

Palavras-chave: Ácidos nucléicos, Purinas, marcadores externos, marcadores internos

\section{Microbial synthesis in the rumen}

\section{Abstract}

To quantify the microbial protein synthesis in ruminant animals is of great importance to assess the nutritional quality of diets. The determination of microbial synthesis is achieved through the use of microbial markers, which are classified: internal (By-products of rumen microorganisms) and external (products administered to animals that are incorporated by microorganisms). Despite the great effort by researchers in recent years, still do not have the ideal marker, and most of these advantages and disadvantages. So the goal of this review is to detail each of the techniques for estimating microbial protein synthesis in the rumen, and analyze and discuss the results obtained using each technique.

Keywords: External markers, internal markers, nucleic acids, purines

\section{Introdução}

Trabalhos de pesquisa indicam que a proteína microbiana responde, em média, por $59 \%$ da proteína que chega ao intestino delgado (Clarck et al., 1992), e esta pode ser estimada por meio do conhecimento da eficiência de síntese microbiana, o que denota a importância do estudo dos mecanismos de síntese protéica bacteriana e dos fatores a eles relacionados. Dessa forma, o aumento na produção de ruminantes pode ser obtido através da maximização da eficiência microbiana.

A quantificação da proteína microbiana sintetizada no rúmen como resultado da fermentação microbiana, é de interesse porque há evidencias de que a 
SERRANO, R.D.C. et al. Síntese microbiana no rúmen. PUBVET, Londrina, V. 5, N. 5, Ed. 152, Art. 1025, 2011.

proteína microbiana pode ser influenciada pela dieta. A importância da proteína microbiana na nutrição de ruminantes está relacionada ao fato desta ser uma fonte de alta qualidade de aminoácidos (AAs) disponíveis para a absorção, possuir uma digestibilidade aparente intestinal de aproximadamente $85 \%$ e um perfil de AAs essenciais semelhantes àqueles do leite e dos tecidos. Além disso, seu perfil de AAs parece ser relativamente constante e pouco influenciado pelas variações na dieta (Valadares Filho e Valadares, 2001).

A determinação da proteína microbiana é uma importante área de estudo na nutrição dos ruminantes. Segundo Chen e Gomes (1992), a contribuição da proteína microbiana no fluxo intestinal de proteína é considerado por muitos sistemas de avaliação de modo mais ou menos constante e com base na quantidade de alimento ingerido. Usualmente a contribuição microbiana é expressa em $\mathrm{g}$ de $\mathrm{N}$ microbiana (NM) por $\mathrm{kg}$ de matéria orgânica digestível degradada no rúmen (MODR), mas os dados experimentais tem mostrado que as variações são grandes (de 14 a $60 \mathrm{~g} \mathrm{NM} \cdot \mathrm{kg}^{-1}$ MODR) (Chen e Gomes, 1992). Estas variações, são devidas à influencia de vários fatores relacionados com dieta e o ambiente ruminal.

\section{Microrganismos Ruminais}

Os ruminantes não podem sintetizar celulose, mas podem digerí-la da parede celular de plantas não lignificadas, utilizando a fermentação ruminal. Além disso, têm desenvolvido uma endosimbiose com os microrganismos, o que thes permite viver de uma dieta cuja principal fonte de carboidratos é a celulose.

A flora microbial é constituída por bactérias, protozoários e fungos, os quais, em sua maioria são anaeróbios obrigatórios (PRESTON, 1986). As populações de microrganismos variam dentro do mesmo animal segundo o tempo percorrido depois da última ingestão do alimento, e entre animais com igual alimentação em diferentes países (Posgate e Ware, 1965). As bactérias criam uma associação juntando-se com microrganismos afins, onde um microrganismo usa os produtos finais do outro para seu crescimento. Existem marcadas interações entre os protozoários e as bactérias, assim muitos 
SERRANO, R.D.C. et al. Síntese microbiana no rúmen. PUBVET, Londrina, V. 5, N. 5, Ed. 152, Art. 1025, 2011.

protozoários ingerem e digerem as bactérias produzindo uma diminuição da biomassa bacteriana, portanto, podendo reduzir a taxa de colonização das partículas do alimento pelas bactérias. Por outro lado, os protozoários competem eficientemente pelos açúcares solúveis e pelo amido com as bactérias, armazenando carboidratos dentro de suas células. Todas essas interações entre microrganismos devem ser estudadas pelos nutricionistas, na procura de melhorar a produção sem afetar a saúde dos animais.

\section{Composição e Digestibilidade da Proteína Microbiana}

Para calcular a contribuição da proteína verdadeira microbiana digestível (PVMD) no intestino delgado, há necessidade do conhecimento da produção de proteína microbiana. Os métodos utilizados para medir a quantidade de proteína microbiana baseiam-se em indicadores microbianos, os quais serão discutidos abaixo. Com relação à absorção verdadeira dos AAs bacterianos no intestino delgado, o CNCPS descrito por Fox et al. (1992), considera que apenas $60 \%$ da proteína microbiana está na forma de AAs disponíveis para a absorção, cujo valor utilizado para a mesma é de 100\%. O NRC (2001) considera o conteúdo em proteína verdadeira da proteína microbiana de $80 \%$ e sua digestibilidade intestinal é igualmente de $80 \%$.

O AFRC (1993) expressa a eficiência de síntese microbiana em termos de proteína bruta microbiana (PBM) sintetizada por mega Joule (MJ) de energia metabolizável (EM) fermentada no rúmen e apresenta valores de 9 a $11 \mathrm{~g}$ de $\mathrm{PBM} / \mathrm{MJ}$ de EM fermentada no rúmen. O CNCPS, descrito por Russell et al. (1992), considera uma eficiência de síntese microbiana de $400 \mathrm{~g}$ de MS microbiana $\mathrm{kg}-1$ de carboidratos totais degradados no rúmen (CHODR) e o NRC (2001) considera a produção de proteína bruta bacteriana em função do NDT, sendo que há uma produção estimada de $130 \mathrm{~g}$ de PBM kg-1 de NDT corrigido. Os CHODR podem ser estimados a partir da matéria orgânica degradada no rúmen (MODR), com um r2 igual a 0,96, encontrando-se que para cada $\mathrm{kg}$ de MODR são degradados $0,86 \mathrm{~kg}$ de CHODR. Esses resultados permitem estimar os CHODR a partir da MODR, uma vez que a maior parte dos 
SERRANO, R.D.C. et al. Síntese microbiana no rúmen. PUBVET, Londrina, V. 5, N. 5, Ed. 152, Art. 1025, 2011.

dados da literatura expressa a eficiência em função da MODR. Vale ressaltar que a eficiência microbiana expressada em relação aos CHODR é mais adequada que na base da MODR, em razão dos lipídeos, que praticamente não fornecem energia para os microrganismos do rúmen, e da proteína bruta, que pode fornecer energia via fermentação dos esqueletos de carbono derivados da desaminação dos AAs.

\section{Marcadores Microbianos}

Os marcadores microbianos podem-se classificar em dois grandes grupos: marcadores internos e externos. Os marcadores internos são constituintes das células microbianas e por isso não precisam ser administrados aos animais experimentais. Por outro lado, os marcadores externos devem ser administrados aos animais experimentais para que sejam incorporados pelos microorganismos ruminais.

\section{Marcadores Microbianos Internos}

Os principais marcadores internos são: Derivados de Purinas, ácidos nucléicos (ácido ribonucleico (ARN) e ácido desoxirribonucléico (ADN)), ácido diaminopimélico (DAPA), ácido aminoetilfosfónico (AEPA), perfis de aminoácidos e o ATP. Nesta revisão faremos ênfase nas primeiras duas técnicas, por serem as mais utilizadas e aceitas na atualidade.

\section{Derivados de purinas}

Nos últimos anos, as pesquisas confirmaram a relação entre produção de proteína microbiana e excreção urinária de derivados de purinas. Porem assumiu-se que a absorção de purinas estaria condicionada à quantidade de proteína microbiana, estimada a partir da excreção urinária dos derivados de purinas (alantoína, ácido úrico, xantina e hipoxantina) Giesecke et al., (1994). Puchala e Kulasek (1992) observaram correlação positiva entre o fluxo de N microbiano e a excreção urinária de derivados de purinas, comparando os métodos dos ácidos nucléicos microbianos e a excreção de derivados de 
SERRANO, R.D.C. et al. Síntese microbiana no rúmen. PUBVET, Londrina, V. 5, N. 5, Ed. 152, Art. 1025, 2011.

purinas na urina, observando uma alta correlação. Johnson et al. (1998) e Vagnoni et al. (1997) também concluíram que a excreção urinária de derivados de purinas apresentou correlação positiva na estimativa do fluxo de $\mathrm{N}$ microbiano no duodeno.

A excreção urinária de derivados de purinas, pelos ruminantes, pode ser usada para estimar o fluxo intestinal de proteína microbiana, uma vez que a excreção endógena de derivados de purinas e a relação quantitativa entre a excreção de derivados de purinas e a absorção de purina tenham sido previamente determinadas (Chen et al., 1996). Segundo os mesmos autores, há diferenças no metabolismo das purinas, sendo já estabelecido que ovinos e Bos taurus diferem quanto ao nível de excreção endógena de purinas e à habilidade de utilização de purinas de origem exógena.

As purinas são prontamente absorvidas como nucleosídeos e bases livres no lúmen do intestino delgado onde são degradadas por enzimas específicas. Por intermédio da ação da enzima xantina oxidase, ocorre a conversão de hipoxantina em xantina e ácido úrico, o qual, é degradado em alantoína, pela ação da uréase (LEHNINGER, 1995).

Na urina de bovinos, ambas as purinas endógenas e exógenas têm composição semelhante de, aproximadamente, $85 \%$ de alantoína e $15 \%$ de ácido úrico; xantina e hipoxantina não estão presentes em quantidades significativas na urina de bovinos (Chen et al., 1990a, b; Verbic et al., 1990; e Chen e Gomes, 1992). Segundo Rennó et al. (2000), o método da excreção urinária de derivados de purinas pode ser utilizado para estimar a produção de proteína microbiana com segurança. A produção de proteína microbiana pode ser estimada em função do consumo de matéria seca, consumo de NDT e da porcentagem de fibra em detergente neutro da ração. Atualmente é aceito utilizar as excreções de alantoína e ácido úrico para representar o total de excreção urinária de derivados de purinas (Castañeda et al., 2009; Souza et al., 2010).

A estimativa do fluxo de proteína microbiana no duodeno, a partir da excreção de derivados de purinas na urina, necessita do conhecimento da relação $\mathrm{N}$ 
SERRANO, R.D.C. et al. Síntese microbiana no rúmen. PUBVET, Londrina, V. 5, N. 5, Ed. 152, Art. 1025, 2011.

purina: $\mathrm{N}$ total dos microrganismos ruminais, que é bastante variável (Vagnoni et al., 1997). Chen e Gomes (1992) utilizaram relação igual a 0,116, a partir de dados da literatura. Valadares Filho (1995) relatou valores médios de 0,176, obtidos de dez experimentos. Dias et al.,(1999), Cardoso et al., (1999), e Carvalho et al. (1997b) obtiveram relações de 0,113; 0,104; e 0,153, respectivamente, em seus experimentos.

A técnica de determinação de derivados de purina (DP) para estimar a síntese microbiana assume que todos os ácidos nucléicos de origem dietética são degradados no rúmen e que, portanto, todos os ácidos nucléicos que deixam o rúmen são essencialmente de origem microbiana. A Figura 1 mostra de modo esquemático o principio deste método. As purinas dos ácidos nucléicos microbianos então são absorvidas, degradadas e excretadas na urina como seus derivados (produtos de degradação), hipoxantina, xantina, acido úrico e alantoina, conforme pode ser observado na Figura 2. A excreção de DP é diretamente proporcional a absorção de purinas (Chen e Gomes, 1992).

Os DP urinários compreendem, portanto, hipoxantina, xantina, acido úrico e alantoina (Figura 2). Estes quatro estão presentes na urina de ovinos, caprinos, cervídeos e lhamas, mas apenas acido úrico e alantoina são excretados por bovinos e bubalinos. Isto porque bovinos e bubalinos tem uma alta atividade de xantina oxidase na mucosa intestinal, degradando, portanto, as bases púricas a seus derivados mais distantes, acido úrico e alantoina. Nos ovinos, a concentração de xantina oxidase no tecido intestinal é praticamente nula (Chen e Gomes, 1992). 
SERRANO, R.D.C. et al. Síntese microbiana no rúmen. PUBVET, Londrina, V. 5, N. 5, Ed. 152, Art. 1025, 2011.

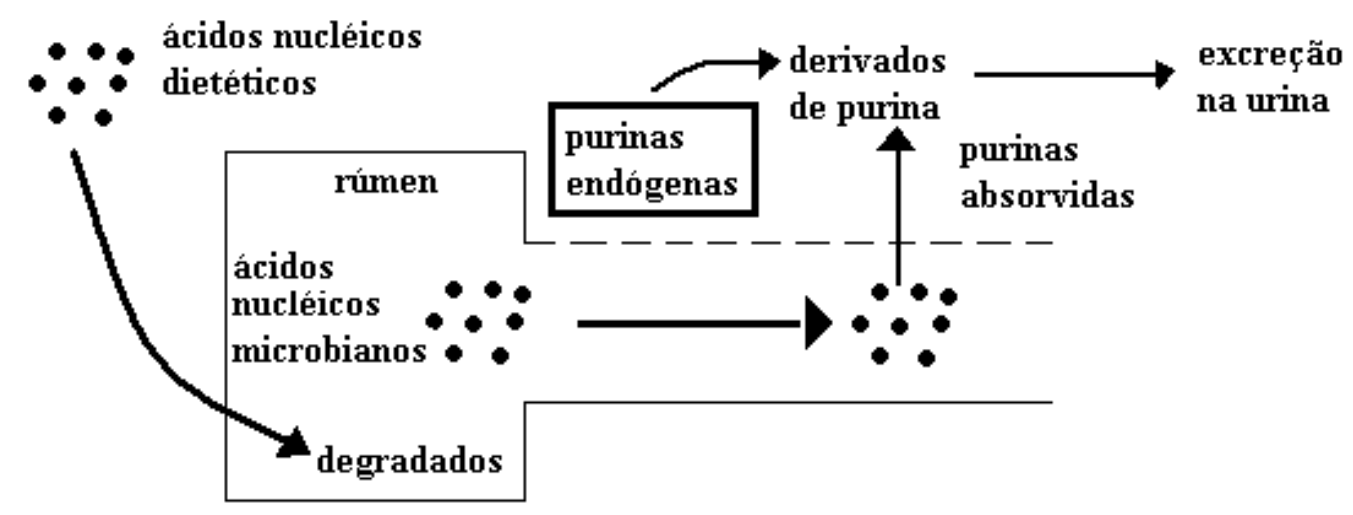

Figura 1. Representação esquemática do principio do método de determinação da excreção urinaria de derivados de purina para estimativa do suprimento de proteína microbiana para ruminantes (adaptado de Chen e Gomes, 1992).

A excreção de DP endógena já foi determinada para diversos animais, incluindo, ovinos, bovinos, caprinos, bubalinos e lhamas. Para ovinos e bovinos, a excreção dos DP de origem endógena esta diretamente correlacionada as purinas exógenas absorvidas no intestino (Chen et al., 1990; Verbic, et al., 1990, Posada et al., 2005). Assim, a excreção de DP pode fornecer uma estimativa quantitativa do fluxo de proteína microbiana se a razão entre purinas e proteína nos microrganismos ruminais for assumida como constante (Tamminga \& Chen, 2000).

Diferenças no metabolismo das purinas tem sido observadas (Tamminga \& Chen, 2000). É importante notar que diferentes equações são necessárias para cada espécie animal. As equações desenvolvidas e validadas ate o momento são para ovinos (Chen et al., 1990) e bovinos (Verbic et al., 1990). Cabe salientar que foram desenvolvidas para animais europeus. Os resultados recentes demonstram que a excreção de DP por animais Bos Indicus é relativamente menor (Paixão et al., 2006, Moraes et al., 2008).

As equações mais usadas para descrever as relações quantitativas entre a absorção de purinas microbianas $\left(X\right.$, em mmol. $\left.d^{-1}\right)$ e a excreção de DP na urina $\left(Y\right.$, em mmol. $\left.d^{-1}\right)$ são as seguintes: 
SERRANO, R.D.C. et al. Síntese microbiana no rúmen. PUBVET, Londrina, V. 5, N. 5, Ed. 152, Art. 1025, 2011.

- Para ovinos: $\quad \mathrm{Y}-0,84 \mathrm{X}+\left(0,150 \mathrm{PV}^{0,75} \mathrm{e}^{-0,25 \mathrm{X}}\right)$

- Para Bovinos: $\quad y-0,85 x+\left(0,385 P V^{0,75}\right)$

Onde: PV ${ }^{0,75}$ representa o peso metabólico (em $\mathrm{kg}$ ) do animal.

As principais limitações desta técnica residem no fato de estar baseada em duas suposições. A primeira é que todo acido nucléico que chega ao intestino delgado é de origem microbiana. Assumir tal fato não compromete a maioria dos estudos, pois realmente os ácidos nucléicos dietéticos são rapidamente e extensivamente degradados no rúmen. Porem há exceções que não podem ser desprezadas. Para certos alimentos de origem animal, principalmente farinha de peixe, tal fato não se aplica. O segundo ponto de limitação refere-se à relação entre purinas e proteína nos microrganismos ruminais ser constante. Ate o momento, não há informação suficiente para tal afirmação.

Para as coletas de urina, com duração de 24 horas, podem-se utilizar funis coletores, adaptados aos animais, conforme metodologia descrita por Valadares et al. (1997). Da urina total coletada em recipiente contendo 200 $\mathrm{mL}$ de H2SO4, a 10\%, no período de 24 e 12 horas, após pesagem e homogeneização, se obtêm alíquotas de $100 \mathrm{~mL}$. Estas amostras devem ter o pH ajustado abaixo de 3 e foram diluídas 3 a 4 vezes, para evitar destruição bacteriana dos derivados de purinas urinários e precipitação do ácido úrico. 
SERRANO, R.D.C. et al. Síntese microbiana no rúmen. PUBVET, Londrina, V. 5, N. 5, Ed. 152, Art. 1025, 2011.

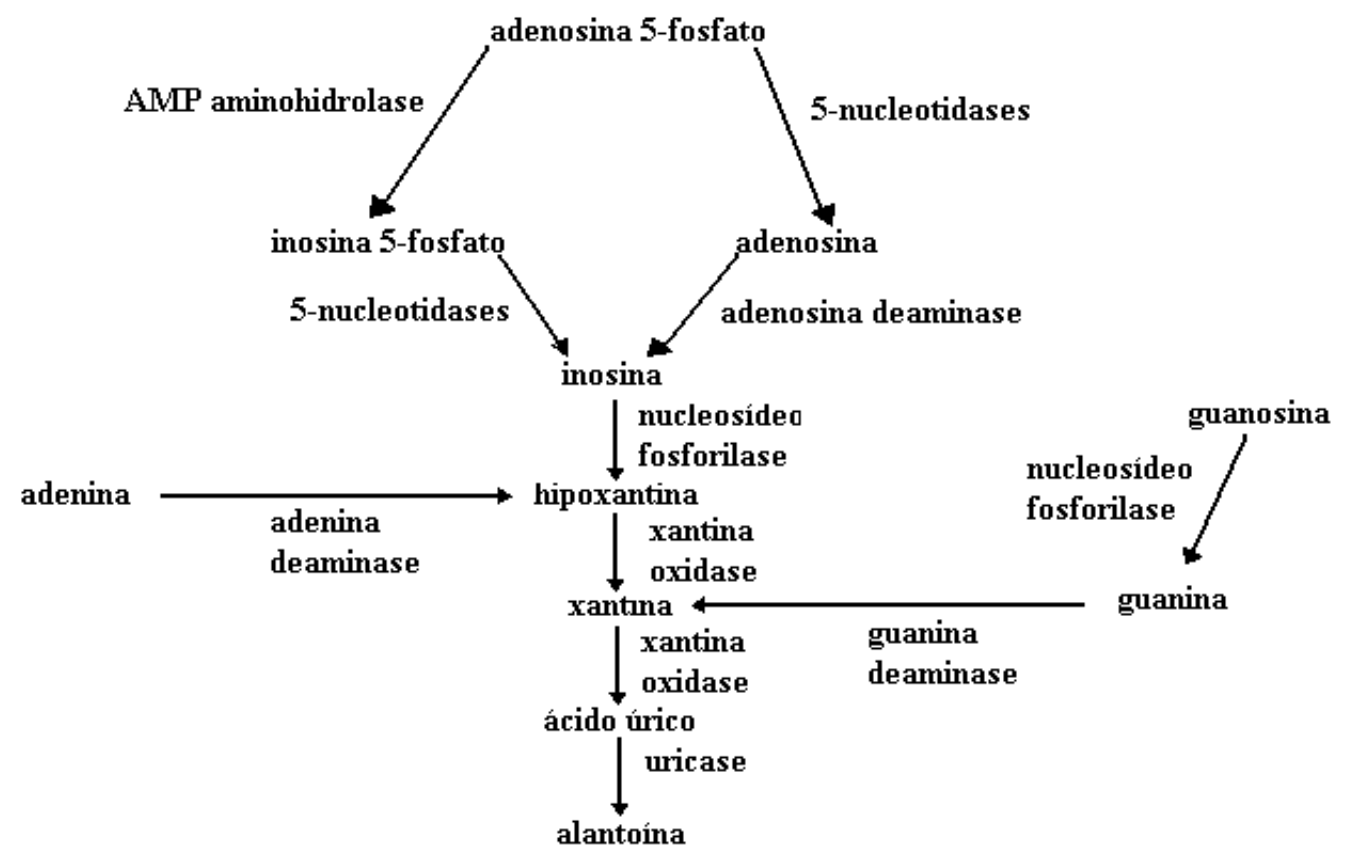

Figura 2. Formação dos derivados de purina a partir da degradação dos nucleotídeos puricos (adaptado de Chen e Gomes, 1992).

As análises de derivados de purinas (alantoína, ácido úrico, xantina e hipoxantina) podem ser feitas pelo método colorimétrico, conforme técnica de Fujihara et al. (1987), descrita por Chen e Gomes (1992). A determinação de alantoína foi descrita por Young e Conway (1942), citados por Chen e Gomes (1992), e baseia-se na hidrólise alcalina a $100^{\circ} \mathrm{C}$ da alantoína a ácido alantóico, que, posteriormente, é convertido em uréia e ácido glioxílico em solução ácida. O ácido glioxílico reage, então, com hidrocloreto de fenilhidrazina, para produzir fenilhidrazona do ácido. O produto forma um cromógeno instável, com ferricianeto de potássio, que pode ser dosado, colorimetricamente, a $522 \mathrm{~nm}$.

O método descrito por Fujihara et al. (1987), para determinação de ácido úrico, baseia-se no tratamento da amostra de urina com uréase, resultando em alantoína, que não absorve ultra-violeta (UV) a 293 nm. Então, a redução na leitura de absorbância a $293 \mathrm{~nm}$ foi correlacionada com a concentração de ácido úrico. Para determinação de xantina e hipoxantina, pode-se converter 
SERRANO, R.D.C. et al. Síntese microbiana no rúmen. PUBVET, Londrina, V. 5, N. 5, Ed. 152, Art. 1025, 2011.

em ácido úrico pela xantina oxidase e medidas como ácido úrico a 293 nm, conforme descrito por Chen e Gomes (1992).

As purinas microbianas absorvidas ( $\mathrm{X}, \mathrm{mmol} / \mathrm{dia}$ ) são calculadas a partir da excreção de derivados de purinas $\left(\mathrm{Y}^{\wedge}, \mathrm{mmol} / \mathrm{dia}\right)$, por intermédio da equação: $\mathrm{Y}^{\wedge}=0,85 \mathrm{X}+0,385 \mathrm{PV}^{0,75}$, em que 0,85 é a recuperação de purinas absorvidas como derivados urinários de purinas e 0,385 $\mathrm{PV}^{0,75}$, a contribuição endógena para a excreção de purinas (Verbic et al., 1990).

$O$ fluxo intestinal de compostos nitrogenados ( $N$ ) microbianos $\left(\mathrm{Y}^{\wedge}, \mathrm{g} \mathrm{N} / \mathrm{dia}\right)$ pode ser calculado em função das purinas microbianas absorvidas ( $X$, $\mathrm{mmol} /$ dia $)$, utilizando-se a equação $\mathrm{Y}^{\wedge}=(70 \mathrm{X}) /(0,83 \times 0,116 \times 1000)$, em que 70 representa o conteúdo de $\mathrm{N}$ nas purinas $(\mathrm{mg} \mathrm{N} / \mathrm{mmol}) ; 0,83$, a digestibilidade das purinas microbianas; e 0,116, a relação $\mathrm{N}$-purina: $\mathrm{N}$-total nas bactérias (Chen e Gomes, 1992). Também pode-se calcular o fluxo de $\mathrm{N}$ microbiano, por intermédio da relação $\mathrm{N}$ purina: $\mathrm{N}$ total.

\section{Ácidos Nucléicos (ADN e ARN)}

A utilização do ADN e especialmente do ARN são baseadas nas altas concentrações destas substâncias que apresentam os microrganismos ruminais (Broderick e Merchen, 1992). Sua utilização como marcadores microbianos remonta-se aos anos sessenta, quando diversos autores observaram que a síntese de proteína microbiana no rúmen estava relacionada com o fluxo total de polinucleótidos (Ellis e Pfander, 1965). Posteriormente tem-se utilizado como marcadores microbianos o total de ácidos nucléicos (Zinn e Owens, 1980; Ushida et al., 1985), o ADN (Arambel et al., 1982) e o ARN (Ling e Buttery, 1978; Merry e McAllan, 1983).

Os dados sobre o conteúdo em RNA das bactérias mostram variação bastante acentuada, de 3,5 e 5,0 g/100 g MS para bactérias aderentes e livres, respectivamente (Merry e McAllan, 1983) até 12 g/100 g MS (JOHN, 1984). Esta variação em parte é atribuída aos diferentes métodos de análise utilizados, mas, por outro lado, reflete também o nível de atividades metabólicas das bactérias. 
SERRANO, R.D.C. et al. Síntese microbiana no rúmen. PUBVET, Londrina, V. 5, N. 5, Ed. 152, Art. 1025, 2011.

Para a estimativa da eficiência de síntese de compostos nitrogenados microbianos, pode-se utilizar as bases purinas como indicador microbiano, determinando-se a concentração do N-purínico ou RNA equivalente em isolado de células bacterianas ruminais de amostras de digesta de rúmen e abomaso, conforme metodologia proposta por Ushida et al. (1985) e Zinn e Owens (1986). Segundo estes últimos autores, o procedimento combina métodos por hidrolise de nucleotídeos com acido perclorico seguido por precipitação de purinas livres com nitrato de prata, para a separação das purinas de outros compostos. O procedimento é rápido, simples, preciso e econômico. A passagem duodenal de $\mathrm{N}$ microbiano é estimada por este procedimento seguindo alimentação com dietas purificadas e semipurificadas. A rápida degradação de ácidos nucléicos dietéticos no rumen conduziu ao uso de ácidos nucléicos ou de suas bases constituintes, purinas ou pirimidinas como marcadores para a determinação da síntese microbiana no rúmen (McAllan et al., 1994).

\section{Marcadores Microbianos Externos}

Os marcadores microbianos externos precisam ser administrados aos animais, para que estes sejam incorporados pelos microrganismos ruminais. 0 procedimento consiste em colocar uma infusão continua do marcador no rúmen dos animais, durante um período experimental, ate alcançar condições de equilíbrio. Os principais marcadores externos são 15N, 32P e 35S

\section{${ }^{32} \mathbf{P}$}

A utilização de radiofósforo $\left({ }^{32} \mathrm{P}\right)$ para a determinação da síntese microbiana tem mostrado ser bastante eficiente. Através da coleta de amostra do liquido do rúmen pode-se medir a taxa de incorporação do radiofósforo in vitro, avaliando dessa maneira a atividade microbiana. O método baseia-se na relação entre a incorporação do fósforo na matéria microbiana e a síntese de proteína, utilização de amônia e produção de ácidos graxos voláteis, em curtos períodos de incubações usando ${ }^{32} \mathrm{P}$ como marcador (Vitti et al., 1988). 
SERRANO, R.D.C. et al. Síntese microbiana no rúmen. PUBVET, Londrina, V. 5, N. 5, Ed. 152, Art. 1025, 2011.

A técnica in vitro de incorporação de ${ }^{32} \mathrm{P}$ para estimar síntese microbiana baseia-se na incubação de uma pequena quantidade de amostra com liquido ruminal em meio tamponado e uma diminuta quantidade de radiofósforo como marcador de proteína microbiana. Com base na atividade especifica do fósforo solúvel (AE) e na incorporação do radiomarcador pelos microrganismos, é possível calcular a quantidade total de massa microbiana gerada, como demonstrado nas equações abaixo:

$A E=A_{32 P s o l u v e l} / P_{\text {total }}$

$P_{\text {incorp }}=A_{32 \text { Pincorp }} \times A E$

$\mathrm{NM}=8,37 \times$ Pincorp

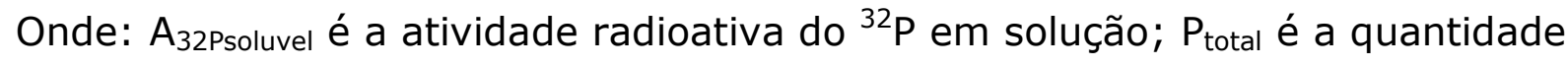

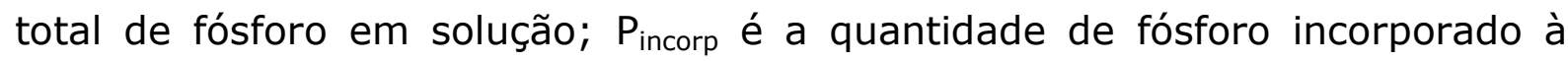

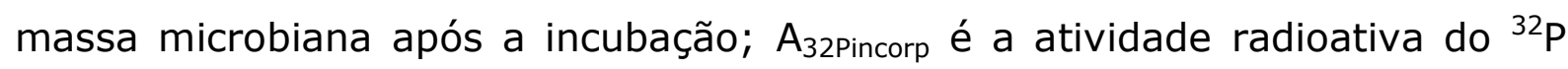
incorporado; e NM é a quantidade de nitrogênio microbiano gerado, assumindo que a relação entre $\mathrm{N}$ e $\mathrm{P}$ na massa microbiana é de 8,37.

\section{${ }^{15} \mathbf{N}$}

A síntese microbiana é determinada in vivo, com a utilização do isótopo pesado do nitrogênio $\left({ }^{15} \mathrm{~N}\right.$ ). Uma fonte enriquecida em ${ }^{15} \mathrm{~N}$ (sulfato de amônio marcado, por exemplo) é fornecida aos animais, ou, ainda, colocada diretamente no rúmen. Esta fonte é metabolizada pelos microrganismos do rúmen e proteínas microbianas são sintetizadas com o nitrogênio marcado. Nas amostras da digesta coletadas no duodeno, determina-se então, a quantidade de proteína microbiana que passa para o restante do sistema digestorio (McAllan et al., 1994). Segundo (Broderick e Merchen., 1992), o ${ }^{15} \mathrm{~N}$ inorgânico tem sido usado amplamente como um indicador para quantificar a produção de proteína bruta microbiana em vivo, o mesmo autor relata as diversas 
SERRANO, R.D.C. et al. Síntese microbiana no rúmen. PUBVET, Londrina, V. 5, N. 5, Ed. 152, Art. 1025, 2011.

vantagens que resultam em utilizar $\circ{ }^{15} \mathrm{~N}$ como um marcador externo. 1) porque $0{ }^{15} \mathrm{~N}$ é um isótopo estável e não é um perigo ambiental. 2) geralmente, ${ }^{15} \mathrm{~N}$ não é encontrado na dieta acima do enriquecimento natural; de ai que, dosagem intraruminal com sais do amônio ${ }^{15} \mathrm{~N}$ em estudos a curto prazo marcaram somente N. 3) ${ }^{15} \mathrm{~N}$ inorgânico é relativamente barato.

\section{${ }^{35} \mathrm{~S}$}

$\mathrm{O}$ isótopo ${ }^{35} \mathrm{~S}$ inorgânico pode infundido no rúmen e ser incorporado na proteína bruta microbiana. Os métodos típicos envolvem dosagem de $\mathrm{Na}_{2}{ }^{35} \mathrm{SO}_{4}$ no rúmen, onde é reduzido a sulfito ${ }^{35} \mathrm{~S}$ e logo é incorporado na proteína bacteriana através da síntese de novo de cistina e de metionina. $0{ }^{35} \mathrm{~S}$ será incorporado também em outros compostos de enxofre, tais como a co-enzima A. Indiretamente, $0{ }^{35} \mathrm{~S}$ marcara proteínas de protozoários. Uma amostra "típica" de micróbios ruminais deve ser isolada para fornecer a relação padrão do indicador. Todavia, a radioatividade acumulada nos tecidos e no leite impossibilita seu uso no alimento. Assim, o uso rotineiro de ${ }^{35} \mathrm{~S}$ como um indicador microbiano em vacas leiteiras seria inconveniente por causa dos problemas da eliminação (Broderick e Merchen., 1992).

\section{Conclusões}

A utilização de metodologias para conhecer a síntese microbiana no rúmen, tem trazido informações importantes para o entendimento e analises de novos alimentos, subprodutos e aditivos na nutrição de ruminantes. Os marcadores microbianos mais utilizados são os derivados de purinas, os ácidos nucléicos (ARN) e $0{ }^{15} \mathrm{~N}$, Os três têm sido propostos como marcadores de eleição por vários autores. Todavia, são escassas as pesquisas comparando estes marcadores, para avaliar a correlação entre eles. As purinas e $0{ }^{15} \mathrm{~N}$ apresentam mais vantagens frente aos demais marcadores, porem podemos dizer que não há um marcador que forneça total confiança. A melhor recomendação na hora de determinar a síntese de proteína microbiana em animais ruminantes seria utilizar mais de um marcador. 
SERRANO, R.D.C. et al. Síntese microbiana no rúmen. PUBVET, Londrina, V. 5, N. 5, Ed. 152, Art. 1025, 2011.

\section{Referências Bibliográficas}

AGRICULTURAL AND FOOD RESEARCH COUNCIL - AFRC. 1993. Energy and protein requeriments of ruminants. Wallington, UK. CAB international. 159p.

ARAMBEL M.J., BARTLEY E.E., DUFVA G.S., NAGARAJA T.G., DAYTON A.D., 1982. Effect of diet on amino and nucleic acids of rumen bacteria and protozoa. J. Dairy Sci., 65, 2095-210.

BRODERICK, G.A., MERCHEN, N.R. 1992. Markers for quantifying microbial protein synthesis in the rumen. J. Dairy Sci., 75(9):2618-2632.

CARDOSO, R.C., VALADARES FILHO, S.C., COELHO DA SILVA, J.F. et al. Influência dos níveis de concentrado sobre a síntese microbiana, $\mathrm{pH}$ e concentração de amônia ruminal, em novilhos $F 1$ limousin $x$ nelore. In: REUNIÃO ANUAL DA SOCIEDADE BRASILEIRA DE ZOOTECNIA, 36, 1999, Porto Alegre. Anais... Porto Alegre: SBZ, 1999. p.258.

CARVALHO, A.U., VALADARES FILHO, S.C., COELHO DA SILVA, J.F. et al. 1997. Níveis de concentrado em dietas de Zebuínos. Eficiência microbiana e população de protozoários ruminais. R. Bras. Zootec., 26(5):1007-1015.

CASTAÑEDA, R. D.; BRANCO, A.F.; CONEGLIAN, S.M.; BARRETO, J.C.; GRANZOTTO, F.; TEIXEIRA, S. Substituição de uréia por cloreto de amônio em dietas de bovinos:digestibilidade, síntese de proteína microbiana, parâmetros ruminais e sanguíneos, Acta Scientiarum. Animal Sciences, v. 31, n. 3, p. 271-277, 2009.

CHEN, X.B.; GOMES, M.J. Estimation of microbial protein supply to sheep and cattle based on urinary excretion of purine derivatives- an overview of technical details. INTERNATIONAL FEED RESEARCH UNIT. Aberdeen, UK: Rowett Research Institute, 1992. 21p. (Occasional publication)

CHEN, X.B., MATHIESON, F.D.D.H., REEDS, P.J. 1990b. Measurements of purine derivates in urine of ruminants using automated methods. J. Sci. Food Agric., 53(1):23-33.

CHEN, X.B., SAMARAWEERA, L., KYLE, D.L. et al. 1996. Urinary excretion of purine derivatives and tissue xantine oxidase (EC 1, 2, 3,2) activity in buffaloes (Bubalis bubalis) with special reference to differences between buffaloes and Bos taurus cattle. Br. J. Nut., 75:317-407.

CLARK, J.H. et al. Symposium:nitrogen metabolism and amino acid nutrition in dairy cattle. J. Dairy Sci., Savoy, v. 75, n. 8, p. 2304-2323, 1992.

DIAS, H.L.C., VALADARES FILHO, S.C., COELHO DA SILVA, J.F. et al. Eficiência de síntese microbiana, $\mathrm{pH}$ e concentrações ruminais de amônia em novilhos $\mathrm{F} 1$ limousin $\mathrm{x}$ nelore alimentados com cinco níveis de concentrado. In: REUNIÃO ANUAL DA SOCIEDADE BRASILEIRA DE ZOOTECNIA, 36, 1999, Porto Alegre. Anais... Porto Alegre: SBZ, 1999. p.258.

ELLIS, W.C, PFANDER W.H., 1965. Rumen microbial polynucleotide synthesis and its possible role in ruminant nitrogen synthesis. Nature (Lond.), 205, 974-975.

FOX, D. G., SNIFFEN, C. J., O'CONNOR, J. D. et al. A net carbohydrate and protein system for evaluating cattle diets: III. Cattle requirements and diet adequacy. Journal of Animal Science, v.70 n.11 p.3578-3596. 1992.

FUJIHARA, T., $\square$ RSKOV, E.R., REEDS, P.J. et al. 1987. The effect of protein infusion on urinary excretion of purine derivatives in ruminants nourished by intragastric nutrition. J. Agric. Sci., 109:7-12.

GIESECKE, D., EHRENTREICH, L., STANGASSINGER, M. 1994. Mammary and renal excretion of purine metabolites in relation to energy intake and milk yield in dairy cows. J. Dairy Sci., 77(8):2376-2381. 
SERRANO, R.D.C. et al. Síntese microbiana no rúmen. PUBVET, Londrina, V. 5, N. 5, Ed. 152, Art. 1025, 2011.

JOHN, A. 1984. Effects of feeding frequency and level of feed intake on chemical composition of rumen bacteria. J. Agric. Sci., 102(1):45-57.

JOHNSON, L.M, HARRISON, J.H., RILEY, R.E. 1998. Estimation of the flow of microbial nitrogen to the duodenum using urinary uric acid or allantoin. J. Dairy Sci., 81(9):2408-2420.

LENINGHER, A.L., NELSON, D.L., COX, M.M. 1995. Princípios de bioquímica. 2.ed., São Paulo: Savier. 839p.

LING J.R., BUTTERY P.J., 1978. The simultaneous use of ribonucleic acid, 35S, 2,6diaminopimelic acid and 2-aminoethylphosphonic acid as markers of microbial nitrogen entering the duodenum of sheep. Br. J. Nutr., 39, 165-179.

MACALLAN, A.B.; SUTTON. J.P; BEEVER, D.E. Rúmen fermentation characteristics and duodenal nutrient flow in lactantin cows receiving two types of grass silage with two levels of concentration.Animal feed science and Technology, v.46, p. 277-291, 1994.

MORAES, K. A. K.; VALADARES FILHO, S.C.; KLING DE MORAES, E. H.B.; LEÃO, M.I.; VALADARES, R.F.D.; PEREIRA, O.G.; SOLÉRO, B.P. Cana-de-açúcar tratada com óxido de cálcio fornecida com diferentes níveis de concentrado para novilhas de corte em confinamento. Revista Brasileira de Zootecnia, v.37, n.7, p. 1293-1300, 2008.

MERRY, R.J., McALLAN, A.B.A 1983. Comparison of the chemical composition of mixed bacteria harveted from the liquid and solid fractions of rumen digesta. Br. J. Nutr., 50(3):701709.

NATIONAL RESEARCH COUNCIL - NRC. Nutrient requirements of dairy cattle. 7.ed. Washington: National Academic Press, 2001. 381p.

PAIXÃO, M.L.; VALADARES FILHO, S.C.; LEÃO, M.I. et al. Uréia em dietas para bovinos: consumo, digestibilidade dos nutrientes, ganho de peso, características de carcaça e produção microbiana. Revista Brasileira de Zootecnia, v.35, n.6, p.2451-2460, 2006.

POSADA, S. L.; GIRALDO, L. A.; BOLIVAR, D. M. Estimación de la síntesis de proteína microbiana a partir de la excreción urinaria de derivados púricos. Livestock Research for Rural Development, v.17, n.6, 2005.

POSGATE, J.R. \& WARE, D.A. Manipulating rumen fermentation. J. Anim. Sci., Champaign, v. 46, n. 3, p. 585-599, 1965.

PRESTON, T.R. Propuestas de metodología de producción adecuados a países tropicais. IN: SEMINARIO UNIVERSIDAD NACIONAL DE COLOMBIA, 1, Palmira, 1986. Resumos ... Palmira: Facultad de Ciencias Agropecuarias, 1986. p. 56-70.

PUCHALA, R.; KULASEK, G.W. Estimation of microbial protein flow from the rumen of sheep using microbial nucleic acid and excretion of purine derivatives. Canadian Journal of Animal Science, v.72, p.821-830, 1992.

RENNÓ, L.N.; VALADARES, R.F.D.; LEÃO, M.I. et al. Estimativa da produção de proteína microbiana em novilhos. Revista Brasileira de Zootecnia, v.29, n.4, p.1223-1234, 2000.

RUSSELL, J.B., O'CONNOR, J.D., FOX, D.J. et al. 1992. A net carbohydrate and protein system for evaluating cattle diets: I ruminal fermentation. J. Anim. Sci., 70:3551-3561.

SOUZA, A. L.; GARCIA, R.; CABRAL, L.S.; PEREIRA, M.L.A.; VALADARES, R.F.D. Coffee hull in the diet of dairy heifers: nitrogen balance and microbial protein synthesis. Revista Brasileira de Zootecnia, v.39, n.5, p. 1141-1145, 2010.

TAMMINGA, S.; CHEN, X.B.; Animal-based techniques for the estimation of protein value. In: GIVENS, D.I.; OWEN, E.; AXFORD, R.F.E.; OMED, H.M (Ed). Forage evaluation in ruminant nutrition. Wallingford: $C A B$ Publinshing, 2000. 
SERRANO, R.D.C. et al. Síntese microbiana no rúmen. PUBVET, Londrina, V. 5, N. 5, Ed. 152, Art. $1025,2011$.

USHIDA, K., LASSALAS, B., JOUANK, J.P. 1985. Determination of assay parameters for RNA analysis in bacterial and duodenal samples by spectrophotometry. Influence of sample treatment and preservation. Reprod. Nutr. Dev., 25:1037-1044.

VAGNONI, D.B.; BRODERICK, M.K.; CLAYTON, R.D. et al. Excretion of purine derivatives by Holstein cows abomasally infused with incremental amounts of purines. Journal of Dairy Science, v,80, p.1695-1702, 1997.

VALADARES FILHO, S. C.; VALADARES, R. F. D. Recentes avanços em proteína na nutrição de vacas leiteiras. In: SINLEITE, 2., 2001, Lavras. Anais...Lavras, DZO UFLA, 2001. p.229247.

VALADARES FILHO, S.C. Eficiência de síntese de proteína microbiana, degradação ruminal e digestibilidade intestinal de proteína bruta em bovinos. In: SIMPÓSIO INTERNACIONAL SOBRE EXIGÊNCIAS NUTRICIONAIS EM RUMINANTES, 1995, Viçosa, MG. Anais... Viçosa: Jard, 1995, p.355-388.

VALADARES, R.F.D., GONÇALVES, L.C., SAMPAIO, I.B. et al.. Níveis de proteína em dietas de bovinos. 3-pH, amônia e eficiência microbiana. R. Bras. Zootec, 1997.

VALADARES, R.F.D.; BRODERICK, G.A.; VALADARES FILHO, S.C. et al. Effect of replacing alfafa silage with high moisture corn on ruminal protein syntesis estimated from excretion of total purine derivates. Journal of Dairy Science, v.82, n.12, p.2686-2696, 1999.

VERBIC, J.; CHEN, X.B.; MACLEOD, N.A. et al. Excretion of purine derivatives by ruminants. Effect of microbial nucleic acid infusion on purine derivative excretion by steers. Journal Agricultural Science, v.114, n.3, p.243-246, 1990.

VITTI, D.M.S.S.; SILVA FILHO, J.C.; ABDALLA, A.L. Phosphorus availability for rúmen microorganisms: effect of different sources. Journal of Nuclear Agriculture na Biology, v.7, p. 186-187, 1988.

YOUNG, E.G, CONWAY, C.F. On the estimation of allantoin by the Rimini-Schryver reaction. J Biol Chem 1942; 142:839-53.

ZINN, R.A., OWENS, F.N. 1986. A rapid procedure for purine measurement and its use for estimating net ruminal protein synthesis. Can. J. Anim. Sci., vol.66, n. 1, p.157-166. 